\title{
Social Television as a New Relationship between Conventional TV and the Audience: An Analysis of its Aims, Processes, and Results
}

\author{
Maria Jose Arrojo ${ }^{1}$ \\ ${ }^{1}$ Area of Audiovisual Communication, University of A Coruña, A Coruña, Spain \\ Correspondence: Maria Jose Arrojo, Audiovisual Communication Faculty, Campus de Elviña s/n, 15071, A Coruña, \\ Spain.
}

Received: May 4, 2015

Accepted: May 19, 2015

Available online: June 3, 2015

doi:10.11114/ijsss.v3i4.854

URL: http://dx.doi.org/10.11114/ijsss.v3i4.854

\begin{abstract}
Social Television comes from the interaction of recent technological improvements and new communicative designs, which leads to a different relation between conventional TV and the audience. 1) The widespread use of mobile devices gives a technological support for new consumption patterns. They have a key influence on the field of communication: they change the aims, processes, and results. Thus, they have generated a truly novel communicative phenomenon. 2) New communicative designs come to play here: a) there is an evolution in the concept of programming, b) the audience has completely changed its role, and c) new preferences come from the interplay between the programming of the TV y the active and creative responses from the audience. This new communicative phenomenon of Social TV requires an adequate framework. It comes, in my judgment, from the "scientification" of a practice with the general context of communication sciences as sciences of design.
\end{abstract}

Keywords: Social Television, technology, programming, Sciences of Design, Social Networks

\section{Introduction}

New media forms are possible because of recent technological innovation which are accompanied by creativity in the designs, phenomena that can be accounted scientifically. In recent years mobile devices have changed the ways in which citizens can access and consume audiovisual content. Nowadays this development has a key influence in the field of communication. De facto, (i) there is a breakthrough in the technological support of the communication used in the last years by individuals and groups; and (ii) the broadcasting channels have a noticeable variation in the aims, processes, and results of communication, leading to completely new phenomena. Moreover, these technological developments have changed the way of working of the broadcast agents. Thus, there is now actual novelty regarding programming, which can be seen in its structure and its dynamics.

Within this setting — recent technological improvements and new communicative designs — "Social TV" is a new and original way of dealing of some broadcasting systems. Ontologically, social TV is the result of an interaction of agents, who actively use a technological instrument -Internet- to comment audiovisual content broadcast on television. They do this talk through social networks. Commonly, this interaction of agents is of autonomous individuals. But they can also be representatives of organizations that have clearly defined objectives. The main goal of this interaction is constructive: it seeks to create a different social reality, at least in virtual terms.

This new social reality emerges from a constructive intention. In addition, it involves a new dynamic of interaction between actors involved in social TV. On the one hand, it creates a new framework of social relations between these individuals (either they be autonomous agents or representatives of organizations); and on the other hand, it allows for a new communication channel between users (interacting agents) and the entity transmitting audiovisual content (that is, the issuing agent, which can be a generalist channel or a thematic channel).

From the point of view of its structure and dynamics, this new television is social. This is the case for several reasons, which are related to their origin, their means and their results:

1) In terms of origin, insofar as they are social agents who participate in it and make it possible as such. They do so based on characteristics of knowledge and following a process of methodological individualism. Thus, they start from individual agents (and, where appropriate, representatives of organizations) who give rise to a new 
social reality. It is a reality different than what allready exists. In principle, they affect or may affect the existing social reality. In so far as the methodological individualism process is known, the result is also known. By means of identifying the behavior of individuals interacting with each other you can know the laws that configurate the evolution of the whole (Hodgson, 1995).

2) This television is also "social" by the type of process used by agents in the social environment where the TV is used. These processes take place in a social environment which is highly developed economically and technologically. They could not take place where Internet use is not possible or were restricted. Social TV is a very sophisticated form of television, which can be accessed from a wide variety of devices (smart phones, electronic tablets, recent computers, etc.).

3) This television is social in terms of results: it offers new forms of social reality within a social context developed. Realities that arise as a result of the interaction of agents are generated over time.

This is a TV built from below: its origin is in the autonomous agents -individuals or representatives of organizations-, which are generating this new television from their decisions, using sophisticated technological supports. By means of the set of the interactions that occur among these individuals, they shared intentions lead to joint action (Tuomela, $\mathrm{R}$. 1996, p. 279). The existence of such joint actions of citizens has forced changes in the entity transmitting audiovisual content: (i) changes in policies television programming, scripting and development of audiovisual content; and (ii) changes in the marketing strategies of broadcasters TV.

Thus, social TV is an innovation in the use and consumption of conventional television to the point that is causing a new reality. In recent years, there has been an increase number of people who use computer or other mobile devices while watching TV (Ley, B.; Ogonowsky, C.; Hess, J.; Reichling, T.; Wan, L.; Wulf, V., 2014, p. 815). Consequently, there has been an increased interaction with the technological devices. But social television goes much further than that: the main characteristic of social TV is in the high level of interaction that develops among users or viewers of audiovisual content, using electronic devices such as support, leading to a new form of communication.

Within a social environment of strong technological development, social TV is a level of interaction much stronger than any existing in the audiovisual field. Through conversations generated on social networks about television content, the agents are creating a virtual reality that has consequences in real life. It was found that there is a direct correlation between the volume of conversations generated on the network and increased consumption of audiovisual content while the TV channel's broadcasts.

From the perspective of the entity transmitting audiovisual content, the conversation generated in social TV has forced both to programmers and writers to consider this virtual community. This has led them to modify content in order to give input to the content generated in this new television. This has also influenced the production time and professional habits. As for marketing departments, already take into account the communities that are generated in social networks , in promotional campaigns for new content or to power the fan phenomenon.

From the point of view of users, there is some dependency relationship in social TV: they are bound to consume audiovisual content in the time when the conventional channel offers them, in order to be able to actively participate in social conversation live. Thus, the interaction between the agents creates a new type of virtual reality that has effects on society itself. We do not talk here about future possibilities, we discusses something much more real than that. It has evolved from a descriptive phase -in which a communicative phenomenon is reflected- to another constative (specify their effects in the social sectors).

The main hypothesis is analyzed in the paper it is that the novelty of social TV involves at least four main aspects. a) Social TV gives the opportunity of transparency in communication: to know who is talking about a content and what is saying. b) This new setting is a suitable scenario for communicational pointcasting strategies. c) This framework will change the relationship between the channel TV and the audience, which will include important variations in the programming policy for the future. And d) It's necessary a new framework to study this new and complex communication phenomena.

\section{Method}

The model proposed in this paper is descriptive in respect of it wants to reflect reality, and is prescriptive, because it wants to target the possible future. The descriptive and prescriptive point of view requires social and artificial components of the communication. On the one hand, the communication sciences are social sciences. This is the case in that concern and provide answers to basic human needs for relationship with others and with the environment (Backhouse \& Fontaine, 2010). Moreover, communication sciences fall within the scope of the sciences of the artificial, because they try to expand human communication possibilities through new designs (Gonzalez, 2008; Arrojo, 2012). These communicative designs have a high degree of dependence on information and communications technology (ICT). 
Within this model of communication with two orientations, descriptive and prescriptive, in this paper it is argued that the study of Social TV belongs, for now, the descriptive level, but is opening new possibilities for prescriptive dimension. This must be contrasted. This requires empirical observation and analysis of the guidelines followed in several directions: from the point of view of content, communication professionals, audience, and media companies. The conclusions drawn must serve to outline the evolution of the communicative model studied.

To address the subject of study, review of the various theories of communication and a profound further reflection was needed. In parallel, there has been observed the use of social networks that are doing the communicative agents. This is the first step for further empirical testing and obtaining results.

To the empirical verify, quantitative data have been used, provided by the major social networks (Facebook and Twitter), the international consultancy The Wit, and by Nielsen, a company specializing in consulting market trends.

The quantitative analysis of data provided by these organizations can establish a framework of study required. This analysis allows two things: 1) define the potential targets by communications professionals and media companies, and 2) establish the processes needed to achieve goals.

In this regard, this paper follows several steps. First, there is a characterization of Social TV as a new phenomenon of communication, which is changing the panorama of TV. Second, there is a theoretical framework in order to grasp this new phenomenon. Thus, the Social TV is considered from the perspective of the science of design as its genuine framework ${ }^{1}$. This viewpoint gives an understanding of this phenomenon of Social TV as a case of applied science (i.e., a solution to a concrete problem) and a characterization of this application to communication in a social milieu. Consequently, internal and external factors are considered. Third, there is an analysis of its relation to social networking, which includes two sides: the existence of an evolution in the concept of programming, and an evolution of the audience itself, with new preferences. Fourth, some final remarks can complete the vision of the topic discussed.

This study is not dealing with a merest possibilities. It analyzes something that is already happening in fact. The topic of the possible implications of the use of technology is not directly addressed, rather this paper already says what those real implications in the work of the agents in society. It is not facing a possibility for the future, but offering to an observable reality. This paper is not focused on the interaction as mere interaction in itself. It analyzes the potencial that is already opening interaction through social television.

\section{A New Phenomenon of Communication}

As a new phenomenon, Social Television combines two factors of communication. On the one hand, Social TV integrates the linear broadcast of audiovisual content generated by the broadcast system; and, on the other, it involves the possibility of enhancing the role of the audience with respect to the narrowcast. Now, by means of the use of the Internet as a technological instrument, a viewer of Social TV can offer an opinion instantaneously at any point regarding the audiovisual content.

The configuration of Social TV is built on the exchange of information and interactivity in two different directions: first, between television broadcast and viewers; and, second, among spectators at play: one with each other. It comes as an exchange that combines two kinds of strategies: (i) a vertical one, where the programmer offers his or her contents in a direct way through the broadcast channel; and (ii) a horizontal relation, insofar as it is oriented towards cross conversation between the agents of the channel itself and spectators, as well as among the viewers: one with each other. The "vertical" contents are increasingly adapted -from the point of view of internal structure- to promote "horizontal" interactions among the participants.

This new phenomenon of communication involves a different form of televised communication, which should be emphasized. In the traditional system of broadcasting audiovisual content, there is a broadcaster that programs the content on a predetermined schedule within the structure of the offerings of content on a channel. The only feedback the channel receives from the audience is the quantitative data of the number of people who viewed the content. Meanwhile, through the new system of consumption of communication, where the viewer is able to communicate and interact with other people who are watching the same audiovisual content, there is an aspect of community. Now the viewer can interact with the factors in play directly, and in real time. This includes the channel that broadcasts the content, the producer that makes it, the actors or hosts who participate, etc. This can be done either at the exact moment, or before or after broadcasting.

Two relevant factors are then the accessibility for the users and the level of interaction during the activity of Social TV. In this new phenomenon, the data shows that the users are really looking for this kind of direct participation regarding audiovisual content. The interactions on Social Networks related to televised content have increased by $171 \%$ during 2012. In the first six months of the year - from January to June 2012 - there were 350 million conversations and social interactions related to conventional TV content (Ghuneim 2012). An additional study, published by the company 
Ericsson, confirms these data: $62 \%$ of viewers used Social Networks while consuming linear television content; $42 \%$ commented on what they were watching while they were watching it; and 30\% said they were willing to pay for the content on which they normally comment in social settings (Ericsson 2013). These data are also corroborated by the Nielsen measurement company in its study "Social TV 2012" (Nielsen 2012a). This institute of public opinion reveals that $41 \%$ of tablet users and $38 \%$ of smart phone users use these devices daily while watching television. They use their devices not only for chatting, but also for shopping or searching for information (Nielsen 2014).

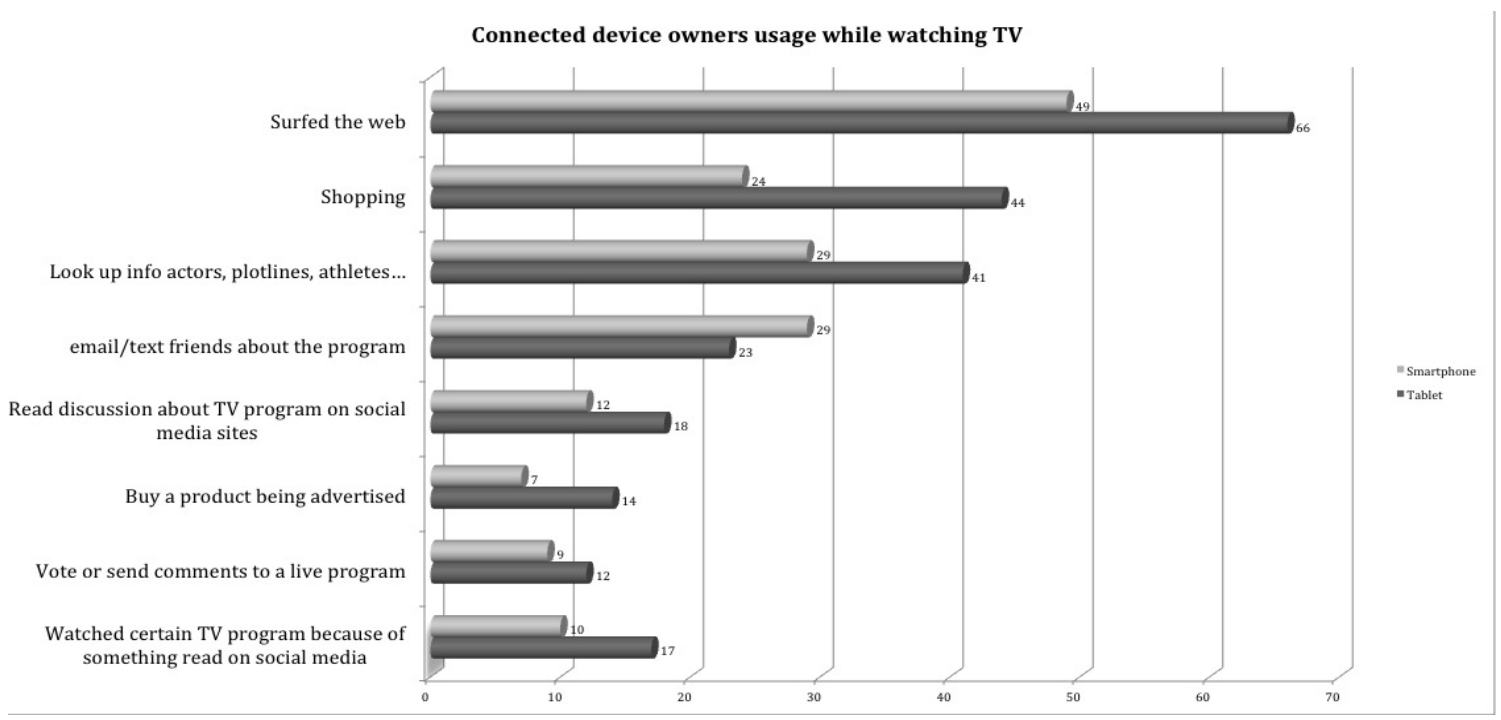

Figure 1. Connected device owners usage while watching TV

Source: Prepared by the author on the basis of Nielsen Connected Devices Report, Q3, 2013

Thus, it seems rather obvious that Social TV plays now a number of relevant roles. Among them are four: a) it enriches linear audiovisual consumption by means of an active conversation for the viewer through new technological platforms; b) Social TV is an opportunity as much for the broadcasting channel as for the content producer to establish marketing and promotion policies regarding broadcasting; c) it feeds the loyalty of the audience around a concrete content; and d) Social TV allows collection of both quantitative and qualitative data regarding the opinions of the audience with respect to the broadcasted content for the first time.

\subsection{Social TV from the Perspective of the Sciences of Design}

Although in its origin Social TV started with some practices, it can be analyzed in terms of "scientification" (in the sense used by Niiniluoto 1993) and, thereafter, it can be characterized from the perspective of the sciences of the artificial. Thus, when this new phenomenon of communication is analyzed, Social TV can be understood as new phenomenon under the science of design. This seems clear insofar as the sciences of communication are disciplines in the context of the artificial. In this regard, the sciences of communication develop new designs to enhance and to extend the possibilities of human communication (Gonzalez 2008). Consequently, through the new television designs, the possibilities of content transmission are enlarged. Moreover, it happens that, at the same time, the users of TV have an active participation concerning the content of the broadcast.

Besides this scientific side - to solve communicative problems with new designs for different aims, processes, and results - and its application to specific cases in the social milieu, there is a technological side, because these designs require technological support to make them viable. In this respect, technology has placed the Internet within our reach. This is a technological development that expands our initial capacity for communication. In effect, as a crucial means for communication, the Internet broadens our communicative capacities as human beings as much in quality as in quantity.

Consequently, the status of the Social TV is twofold. On the one hand, because the sciences of design are the applied sciences, they are oriented toward resolving concrete problems (Niiniluoto 1993). They work on the realm of the artificial or the sphere of the human-made, as it happens with the Social TV. On the other hand, the accomplishments made by new technological media (Internet, Social Networks, Social TV, etc.) must be studied as means of enhancing human communication, an expression of the usual development of the sciences of design. These new technological media are what make the aims, processes, and results possible.

For Herbert Simon, the sciences of the artificial are occupied by how things must be; they deal with designing artifacts 
in order to achieve goals (Simon 1996). This is the case of the sciences of communication, in general, and of the study of Social TV, in particular. Both can be analyzed from the perspective of the sciences of the artificial, to the extent that they begin with a design the way of the aims sought, the processes developed, and the results obtained.

Certainly, the realm under scrutiny is human-made, such as programs, channels of transmission, etc. Furthermore, this sphere is accompanied by technological innovations (Internet, Social Networks, etc.), which are also artificial. Social TV is a domain that was born with an applied finality: it seeks to offer a solution to concrete problems. Among these problems is the demand of the audience to talk about the content they are watching in real time. However, the channel also needs the audience to consume their content online. In addition, the advertiser faces the challenge of understanding their audience in order to increase their profit margins or reputation.

Three elements are needed for the analyze Social TV in terms of the applied science of design: aims, processes, and results. The possible aims are numerous: (i) target the largest audience possible on the web; (ii) increase consumption of the audiovisual content on linear broadcast; (iii) gain a greater understanding of audience opinion regarding the audiovisual content; (iv) contribute to the fan phenomenon surrounding a particular content; (v) become more attractive on the surface to bring in revenue through advertising; etc.

The processes depend on the strategies of used by businesses firms as much on the aims of communication do. With this new phenomenon of communication, each medium must establish the processes it will follow. These decisions directly depend on programming policies and the distribution of content. Thereafter, the results - expected or not — will follow. It is clear that the results depend on criteria such as manageability and utility of the processes. The results depend on internal factors (communicative ones), but also on external components (social, economic, legal, political, etc.). When Social TV is understood this way, the framework of the science of design fits quite well for its study.

\subsubsection{Internal factors of Social TV}

Among the internal factors are those that are directly part of the aims-processes-results pathway. This pathway must be understood by the sciences of communication with respect to sciences of design, and furthermore must be oriented by the sciences of communication. Their commitment of the applied sciences is to solve concrete problems (Niiniluoto 1993). This requires two tasks: first, the anticipation of the possible future by means of prediction; and, second, to give the patterns to guide the practical action (i.e., prescription). In effect, the sciences of design intend to predict the future, in order to later be able to prescribe adequately (Gonzalez 2007a). Thus, they intend to elucidate guidelines regarding what must be accomplished in order to achieve the goals set out.

From this internal perspective of applied science, the first thing the sciences of communication should do is to identify the internal factors that characterize Social TV, in order to be able to analyze them later. This attempts to clarify the internal joints (the structure) and the dynamic setting (the mode in which it changes) of Social TV. This allows identity and points of intersection with Social Networks to be grasped, while keeping in mind the aspects of Social TV that are distinct from any phenomenon of communication that has previously existed. Moreover, interaction with Social Networks revolutionizes the field of communication. These new means of communication have made it possible to join millions of users together from across the world. According to figures, Facebook presented in April of 2014, it had reached 1.28 billion monthly active users, and over 1 billion monthly active mobile users.

Number of monthly active Facebook users worldwide (2008-2014)

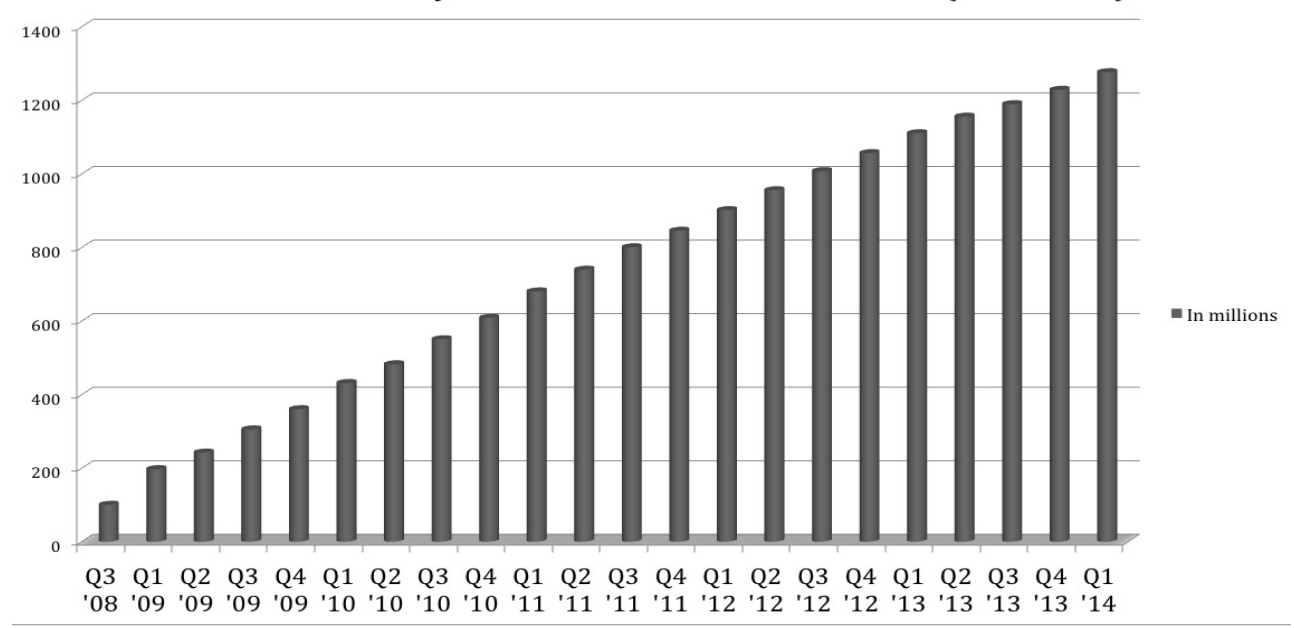

Figure 2 Number of monthly active Facebook users worldwide (2008-2014)

Source: Prepared by the author on the basis of Statista 2014 
This means that one in every seven people on the planet has an account on this Social Network and uses it. In the first quarter of 2014, Twitter declared that they had registered 255 million active users worldwide.

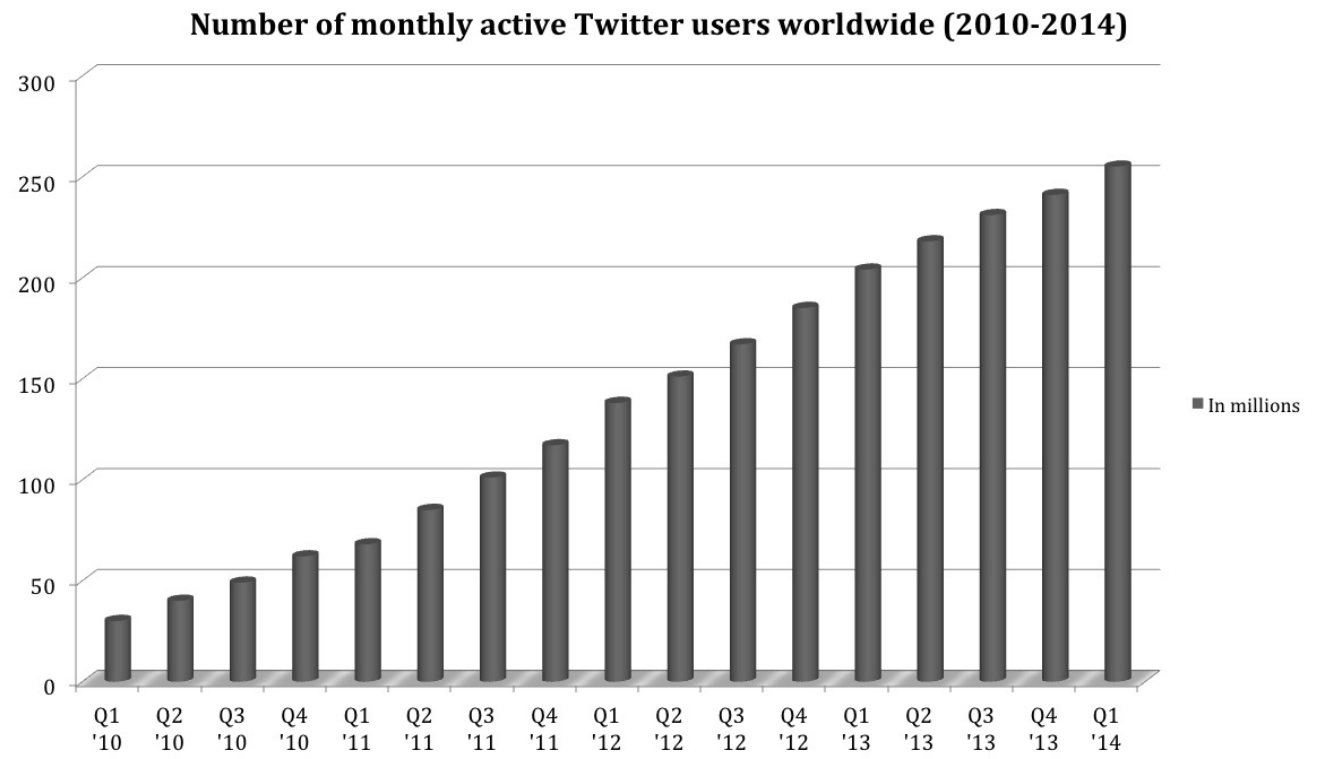

Figure 3. Number of monthly active Twitter users worldwide (2010-2014)

Source: Prepared by the author on the basis of Statista 2014

What is moving these millions of people to put themselves up on these technologically-based social structures, making these structures one of the largest communication forums across the world? There are various factors involved here:

First, simplicity: the possibility of generating conversation in a very simple way. Anyone can broadcast. Social Networks tabulate a dialogue in which each of the actors that interacts is on the same level as the rest.

Second is the factor of deeper veracity: that which is expressed corresponds to that which is thought. When dealing with a technological development in which each user leaves a trail, users are impressed with a greater sense of sincerity. Veracity brings with it the concept of credibility and, therefore, the existence of real trust.

Then, thirdly, it comes transparency. In this context, transparency is seen in terms of an apparent lack of filters. Users have a greater sense of transparency when they are unaware of the manipulation of content.

Fourth, it is fitting to point out immediacy as another of the internal elements of Social Networks. This is the great value of Twitter, created in 2006 by Jack Dorsey. Given that it affords the possibility of narrating actions in the exact moment in which they occur, Twitter features this characteristic of immediacy. The foundation of Social TV is to offer the opportunity to comment on audiovisual content in real time, and this is exactly what Twitter does.

Fifth comes versatility, which is a concept that usually accompanies immediacy in use. Programs are given life while broadcasting, but the audience perceptions of the program can vary over the course of the broadcast. The Social Networks, primarily Twitter, are the best catalysts of this evolution. This is reflected in the appearance of new hashtags and new conversation suggestions during the direct TV broadcast.

Sixth, it fits to highlight the feature of offshoring. Social Networks allow exchange of comments regarding industrial output (in this case, televised output) from one country to another. They are also a suitable means of recommending consumption of televised content or influencing audience perception of a particular content. The Social Networks allow this to be done with geographical perspectives and cultural distinctions. This enriches and, at the same time, complicates the conversation and the control that the players in the television industry have over their products.

Seventh, usability stands out with respect to the content. It deals with the ease of maneuvering within the interface, which can be used as a new means for diverse ends. Without a doubt, this is one of the factors that have allowed the number of users across the world to continue to grow.

\subsubsection{External factors of Social TV}

All in all, there is context of individuals and groups mainly in developed societies. To the extent that Social TV, Internet, and Social Networks are constructs of human minds, they maintain individual and collective relationships with many 
external factors: It is fitting to affirm that they intend to offer an answer to timely problems or issues through concrete aims and processes in order to meet goals. Some of these external elements are identified below:

a) Diffusion is the first, most obvious feature. This is noted in the high number of users on Social Networks. On these networks, any content can exert a strong influence and unfold into "grand rounds" in a short period of time. Social Networks have, in many ways, become a loud-speaker for the social life of society.

b) Plenty of acceptance is the second most noteworthy aspect. People value the ability to communicate directly. The fact that $40 \%$ of Social Network users comment on content they are watching on TV at a particular time is a clear test that this technological development has widespread acceptance.

c) Age is the third characteristic to consider. Age is one of the most influential sociological factors modulating variable behavior on Social Networks. According to data offered by Nielsen about the behavior of people who use Twitter while watching television, younger people (between 18 and 34 years old) are especially active around programs with fiction plots. They comment directly on the aspects they like most about the scripts or, on the contrary, they criticize that which least impresses them. The profiles of people in an older age group (between 35 and 44 years old) are good catalysts for taking the pulse of the aggregate of content. This is due to their overall, greater activity, and their more generalized way of talking about any type of television content while they are watching it (Mouseler 2012).

d) Cultural standards and geographical area are also influencing factors. Audience behavior varies across the world with respect to many technological developments: in this case, regarding Social Networks. In 2012, the audiovisual industry analyzed the phenomenon of Latin American networks for the large boom that Social TV had on this continent. The consultant The Wit broadcasted a report in which it tried to find an explanation for this phenomenon (Servy 2012).

There were three proposed explanations: a) the high level of penetration of Facebook and Twitter in Latin America; b) the high level of social network activity within this society overall; and c) the potent force of the Latin America audiovisual industry on social networks.

Two years after the birth of the Social TV phenomenon, the Latin American market continues to dominate the Social TV. At the end of 2013, 5 Spanish-Speaking countries, and 5 Latin American are in the Top 10 of the most active commentators of TV premieres in social media. For example, Brazil is the World's number 1, Spain is Europe's number 1, and Chile is the most active country per inhabitant. In 2013 USA had a few big social TV events, but the US average social activity was lower than in Latin or European countries (The WitspottER 2014) ${ }^{2}$.

\subsection{Social TV and Social Network}

Certainly, Social TV is a new opportunity and a new challenge for the audiovisual sector. To the extent that social networks constitute a key element for the development of Social TV, internal and external factors that characterize them also require conventional channels to develop their own strategies in this digital world. The new designs should accommodate the characteristics of these emerging frameworks and their languages. Furthermore, the offerings of communication that the channels and producers develop for Social TV should complement the programming policies on conventional TV.

There is, therefore, a combination of various aspects. First, there is a new artifact (Social Networks); second, a concrete strategy of communication is offered (as part of a design, with aims and processes, in order to try to achieve certain results); and, third, there is a perceived need of the audience to interact. All of this leads to the idea that Social TV is a new phenomenon of communication on the Internet.

With respect to this phenomenon, numerous experts have already considered "Social TV." They have left a few definitions regarding this new expression: "It converts the act of watching TV into a social activity, and it has the objective of giving the viewer the sense of watching with others" (Erik Boertjes, Jente Klok, Omar Niamut and Martijn Staal 2009).

Certain fundamental aspects of Social TV are prominent: (i) new technological devices are used, (ii) direct communication among viewers is made possible with these devices, and (iii) through this interaction, the feeling of community around televised content can be generated or enhanced.

Regarding the use of technological devices, after a preliminary period of observation, a few conclusions can be made. For example, the selection of one technological device or another - the selection of a particular social networkdetermines the message. This can be explained by the observation that the behavior of the users on each of the social networks is not the same. They adjust themselves to the internal characteristics of each of these new media. Twitter was built as an ideal medium for generating conversation on the Internet around television content. Furthermore, a study done for advertisers by Twitter in the United Kingdom about Social TV revealed that $60 \%$ of Brits use this social network while watching TV and 40\% of Twitter traffic during Prime Time refers to television (Twitter 2012). 
In June 2012 - according to data managed by the American company of audience measurement Nielsen - $33 \%$ of active Twitter account holders used the Network to talk about the content they were watching on TV. The internal characteristics of this network allow it to be at the center of any conversation. This has ensured its success in the televised world (Webdale 2012). However, the study by Nielsen also highlights the importance of Facebook for determining content. The data reveal that content is recommended on Facebook and then receives comments on Twitter (Nielsen 2012b).

\subsection{Evolution in the concept of Programming}

Throughout the previous discussion it is apparent that Social TV develops certain patterns, which are different from those established in conventional television programming systems. The key fact - that the viewer wants to actively invest in the process of communication - requires new dynamics to be put in place that complement the policies of conventional programming. The new objective is generating communities in the context of audiovisual content. If the user experience can be enriched using the networks, a greater faithfulness to audiovisual content will develop.

Even then, this new phenomenon far from being a problem for the stability of the conventional model of communicative business firms. On the contrary, it helps the conventional model. The new processes contribute to sustaining the very models of communication and business of the broadcast system. Those responsible for the content have already learned that the greater the degree of conversation on the Internet around a concrete content, the greater the increase in the audience of the linear broadcast on the conventional channel.

Until Social TV came on the scene, to program was understood as meaning an intentional human action inside a social media; based on human communication, as much linguistic as visual, and that has aims, processes, and results that can be very distinct. The programming was conceived as a whole. That is to say, it was conceived as an organized proposal of televised products temporally structured. This is the motive behind the conventional audiovisual industry mistrusting, from the very beginning, the technological developments that allowed the user to be the owner of his own free time. The business model of broadcast television is compromised if consumers are allowed to decide what content to watch, in which medium, and on which schedule. This model is sustained on a linear consumption of programs.

However, what the advent of Social TV does is complement this organizational model of the production of televised communication. Social TV has been introduced as a new opportunity to give continuity to the traditional business model, which is based on bringing together the greatest number of people as consumers of a concrete audiovisual content at a particular time.

When there is a greater expectation generated on the web regarding a program, the conversation and perceived need to directly view the program also increases. The viewer has to see the audiovisual content at the time the programmer decides to broadcast it in order to be able to participate in the conversation in real time. In some form, this technological development assures the continuity of the fluid model of television consumption.

In this context, in order to be able to create such events and a feeling of community around an audiovisual space, the conversation should not be limited to the moment of broadcast. Those responsible for the content would then be required to develop complementary promotional and marketing strategies on the web. These strategies should be developed with a clear design arising from clearly identified objectives, and with a thorough understanding of the behavior of Internet audiences. Only in this way can the "fan phenomenon" grow more powerful.

Precisely one of the factors that has played a key role in this boom and rapid growth of Social TV is the need the viewer feels to share his or her experience as a user, especially to share directly and while the program is being broadcast live. This is a differential element that has defined a 'before and after' in the history of television and, necessarily, influences programming policy.

If we see in retrospect, one first notices that the channels did not have a suitable framework for understanding this sociological change in the relationship between the user and the audiovisual content that came as a result of technological development. The initial reaction was to resist the change and try to ignore this reality.

Now those responsible for the content must develop new promotional, marketing, and programming strategies. While doing so, they must keep in mind the existence of new interfaces and the possibility that the audience may participate in the content. These new strategies should be designed before, during, and after the broadcasting of the content. The objective is to try to lengthen the conversation around these programs as much as possible in order to guarantee an increase in audience on the conventional channel and a greater fidelity to the content. 


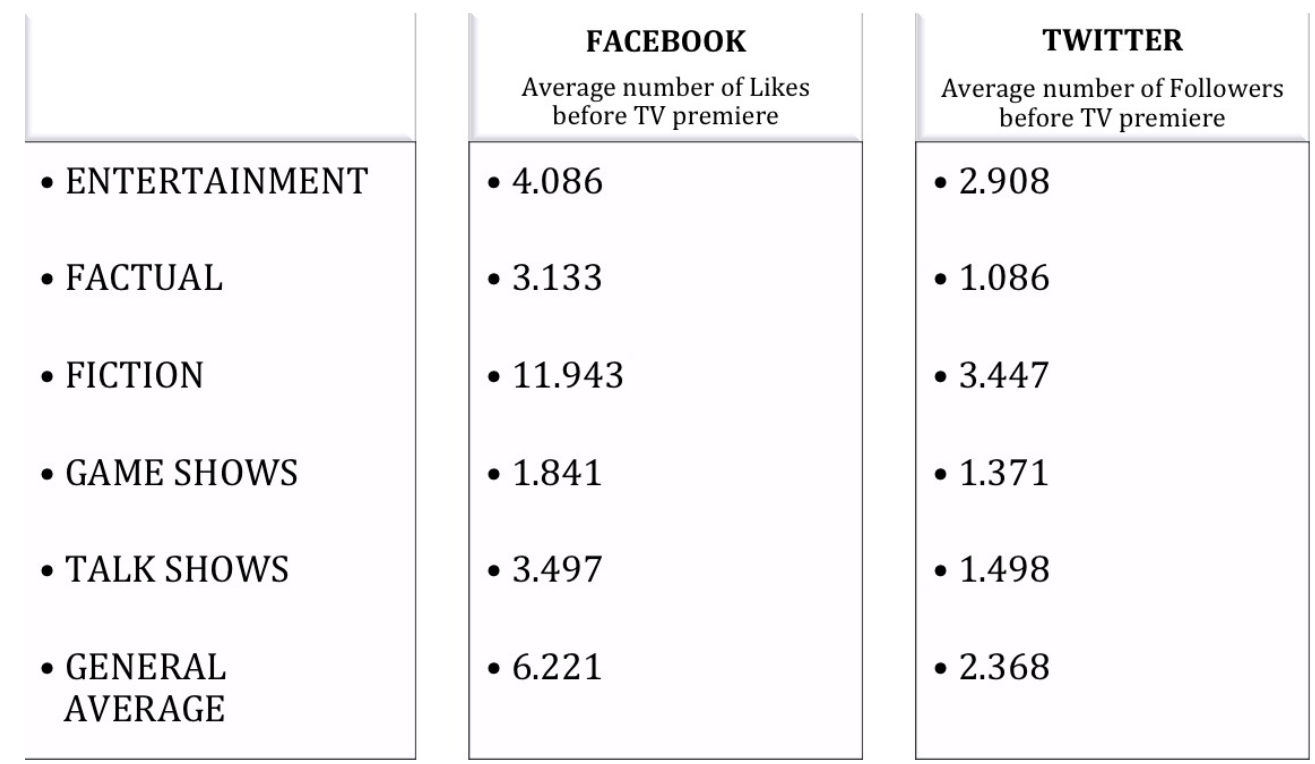

Figure 4. Facebook and Twitter activity in anticipation of premiers (January-August 2013) ${ }^{3}$

Source: Prepared by the author on the basis of The Wit 2013

These campaigns designed for before, during, and after the broadcast are also influencing the processes of script writing and production of the audiovisual content. It is necessary to keep in mind the possible utilization of these companion devices, or second screens, by the viewer starting from the moment of conception and pre-production of the audiovisual content. This, then, leads us to consider a few factors:

1) The programs that previously were recordable using a direct method, to delay broadcasting — which carries an important cost savings - , now must be broadcasted directly, in order to be able to integrate the conversations around these shows. 2) When the scripts of the dialogues or host interjections are written, quotes are already being considered that can be easily be repeated by the audience. In the running order of entertainment formats specific sections arise. These echo the conversations taking place on the Web. 3) The production of premium content is also being planned and conceived as extras in order to win the loyalty of the Social Network users.

All of these changes are being made to ensure that the people in charge of the channels and those in charge of the designs of the programming, consider the behavior of the Social TV users. Programmers must make decisions about production of communication based on a few professional criteria that go beyond choosing and distributing products of communication (tv formats) on a schedule. This broadens the conceptual horizon of programming. This horizon is beginning to be understood as the very intention of the communication by a television channel: it is a we-intention in its own sense (Tuomela 1996).

Nowadays, "products of communication" are not only understood with respect to the pieces that are broadcast on conventional TV, but also those that define the strategy: campaign of communication, promotion, and marketing that can be revealed the Internet. The concept of "programming" evolves in this way. Programming is not a single strategy of compiling audiovisual content but integrates factors like duration, the broadcast schedule, or the offerings of competing channels in this process. Programming becomes the result of the aggregate of social actions that come to determine products of communication (Arrojo 2012).

Television - and, by extension programming, understood as a "design of communication" — is a professional practice which can be "scientificized" (in an initial phase to get actual science, in terms of applied science). A first phase of observation, in which we still find ourselves, has been necessary. It is exactly here where Social TV can contribute to producing a qualitative leap: the step of programming, understood as a professional activity broadening the field of communication as a science of design, which requires predicting the possible future and prescribing guidelines for action.

\subsection{Evolution in audience behaviour}

Reliable data about the behavior of the audiences in the setting of Social Networks were provided in the 2012 report from Nielsen (Nielsen 2012b). They reflect a simultaneous use of smart phones and tablets while watching television. This increase in multitasking is important. However, just as or possibly more important than the very fact that the trends continue to rise, is being able to understand why this happens. The data from this audience-measuring company show 
that $82 \%$ of people who have a second mobile device as an interface — tablets or phones of the latest generation — do not feel satisfied only with the linear consumption of audiovisual content. They need to participate in Social Networks while watching television. Furthermore, 58\% of those who use these devices want to actively enrich their user experience by searching for information about the program they are watching.

Another important aspect to consider is the behavior of these users with regard to advertising. In recent years, the audience has tried to avoid advertising that interrupts the broadcast of linear televised content. However, the Nielsen study reveals that $41 \%$ of mobile device users search for information about products that they have just seen on a television commercial; $36 \%$ search for coupons or special offers related to a television commercial; and $67 \%$ make purchases. Social TV does audiences stop avoiding advertising, but also they become more active when encountering advertising content related to their interests. This audience behavior opens up new opportunities also for marketing and publicity.

Furthermore, Networked Insights, a North American company that analyzes audience behavior on the Internet, emphasizes this newly created opportunity: change in the business model will be directly affected by this new understanding of the audience. In this respect it is clear that

"all of this social intelligence provided the Web the information needed to give the audience the content they wanted, and the optimal moment for the social conversation to continue to increase, as would be with new viewers... the Social Networks are going to be the key for the communications of the channel, in order to maintain the interest of the audience, to try to maximize the Prime Time impact, and to motivate promotional activities" (Networked Insights 2012).

This is clearly seen when one works with live broadcast content. Super Bowl XLVII was an event with one of the largest audiences in the history of television: there were 108.7 million viewers. This game generated 26.1 million tweets before, during, and after the event: "When the lights shut off in the middle of the stadium, the audience went to Twitter, a positive test that the way in which the audience interacts with television programming has changed forever" (Nielsen 2013).

In the case of the MTV Video Music Awards, for example, this event generated 19 million tweets, and over 10.2 million people viewed approximately 30 tweets on average each about this music event in 2013 (Nielsen 2013).

The second place in the ranking of the most shared content is for drama series. These content get good results in the Social TV when they reach good levels of previous conversation and there is an engaged community. Thus, for example, over 9.1 million people saw one or more of the 1.2 million tweets sent about he Breaking Bad series finale.

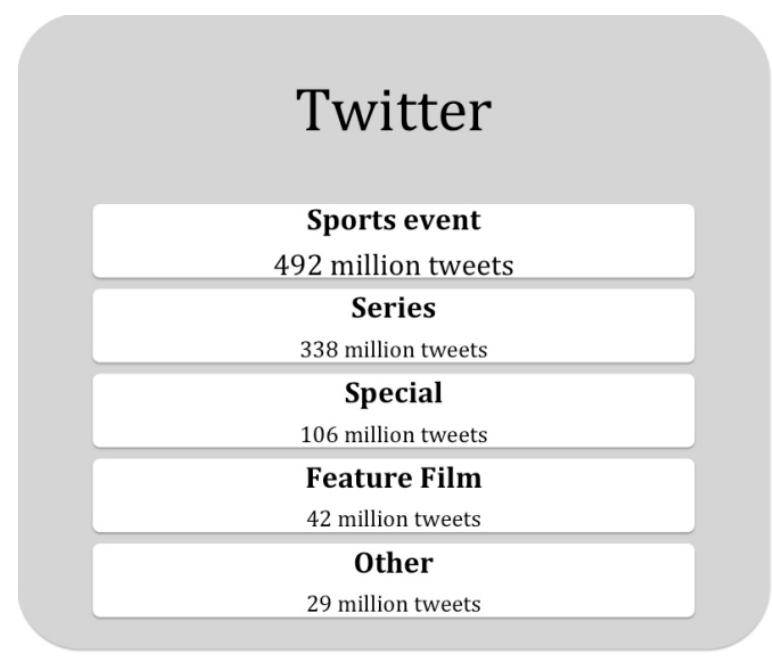

Figure. 5 Most tweeted program types

Within this sphere, one of the challenges in this new model is being able to understand the behavior of the audience in-depth. In this respect, some indicators are already beginning to surface:

(i) The programs that generate the most comments are those that are directly broadcast, such as debates, contests, or reality shows. However, there is also a large conversation with clearly localized roots surrounding fiction content like modern or historical dramas. (The WitspottER 2013). 
(ii) The largest conversation traffic on the web coincides with the broadcasting of live programs. However, this conversation can be moved forward or lengthened on the web as a function of the communication strategy of the channel. The longer the conversation engages the attention of the audience, the greater empathy the user expresses related to the content. It is shown that, for each $9 \%$ increase in volume of messages on Social Networks before the premier of a program, there is a $1 \%$ increase in the audience of the premier (Nielsen 2011). The series "The Vampire Diaries" from the American channel CW is a clear example of how the conversation can be maintained and of the community that created an environment for this audiovisual content, even lasting during the months in which the series is not broadcast (Ghuneim 2012).

(iii) Social Networks become drivers of setting guidelines set primarily through Facebook. According to the data from Nielsen, $46 \%$ of people who are active on Social TV start watching a particular television content because someone recommended it to him or her on Facebook. However, this figure declines to 14\% in the case of recommendations made on Twitter (Nielsen 2012b).

Therefore, Social TV will allow the building of business models that are complementary to those that already exist. Furthermore, this can happen in a way that goes beyond what currently exists with the emerging integration of Social Networks in promotion of televised content. Through the "second screen", it will be possible to develop a scheme of publicity that is specific and complementary to conventional TV advertisements, with direct links to content generated by the advertising brand.

\section{Discussion}

The phenomenon that Social Networks have become an experience of consumption of audiovisual content in an immediate, shared conversation by an entire community of users, is both recent and relevant. This phenomenon allows for a dialogue with the audience that, for the first time, exposes their interests, their needs, and their opinions about the content that is offered to them. When dealing with this situation, the channels and advertising businesses are no longer satisfied with knowing the number of "likes" or "followers" that a particular content obtained on the primary Social Networks. Now they are looking for qualitative data and explanatory analyses of the audience behaviors. This data is already being collected thanks to the businesses that specialize in the measurement of conversations.

Nevertheless, from now on social webs or the applications created to generate community around a particular content or genre, thereof, are given a defined role. These social webs or apps will try to diminish the prominence of the big Social Networks, even though they are not exclusive. In 2012, time dedicated to mobile apps and mobile Internet use increased to $63 \%$ (Nielsen 2012b).

Television channels are also beginning to see their web pages and apps as an opportunity to establish a faithful following and win new audiences. They will try to direct the conversation by spreading content that lengthens the conversation. This translates into an increase in audience and the "fan phenomenon." They will probably achieve a level of users that is less than the big Social Networks, but it will allow the producer or channel that has the rights to the content - and the advertiser - to win a much more royal profile in their fan niche. The future seems to be headed towards the construction of communities of followers of audiovisual content on the Web. This will allow an ever-increasing segment of the audience access to more effective publicity campaigns.

With respect to programming, the Social Networks are presented as an ally for generating expectations regarding the broadcast of content, above all on Prime Time. They are also allies, at least for a certain period of time in the maintenance of this traditional model of programming. The direct consequence of this is the presence of a higher degree of the spectacular nature of competitive programming. However, a profound but corresponding change in the concept of programming occurs and is diluted by the commitment of promotional and marketing content. It is necessary to promote the online conversation in order to lengthen the life of the audiovisual content and obtain, in this way, higher levels of audiences.

Nonetheless, the field needs time to mature in order for the TV channels and the audiovisual content producers to learn to pull out the largest catch possible from this new phenomenon of communication. This will contribute to reporting greater economic profits, to the extent that the profiling of business models that must accompany this new consumption continues. It is clear is that there will continue to be a wider hole between the agents of the audiovisual sector that understand this new phenomenon and those who remain fixed on their metric systems, developing conventional content, advertising, and marketing. The audiovisual sector is bearing witness to the process of scientification of an emerging professional practice. Steps in this direction must continue, for this could already be forming part of the sciences of communication as applied sciences of design, and in such a way that they could contribute with the double effect of prediction and prescription (Gonzalez 2007b). 


\section{Acknowledgements}

To Professor Wenceslao J. Gonzalez for his never ending support, and for his brilliant ideas.

\section{References}

Arrojo, M. J. (2012). Communication Sciences as Sciences of the Artificial: An Analysis of the Digital Terrestrial Television. In New Challenges to Philosophy of Science, edited by Hanne Andersen, Dennis Dieks, Wenceslao J. Gonzalez, W. J., Thomas Uebel, Gregory Wheeler, 325-336. Dordrecht: Springer.

Boertjes, E., Klok, J., Niamut, O., \& Staal, M. (2009). ConnectTV: Share the Experience. In Social Interactive Television: Inmersive Shared Experiences and Perspectives, edited by Pable Cesar, David Geerts and Konstantinos Chorianopoluds, 187-201. Information Science Reference: Hershey, PA.

Ericsson, Consummer Lab. (2013).10 Hot Consumer Trends 2013. Retrieved March 30, 2014, from http://www.ericsson.com/res/docs/2012/consumerlab/10-hot-consumer-trends-2013.pdf.

Ghuneim, M. (2012). Social TV in a New Age of Media Consumption. Conference presented at Mipcom 2012, Cannes, France, September 18. Retrieved March 25, 2014

http://blog.mipworld.com/2012/09/mark-ghuneim-social-tv-in-a-new-age-of-media-consumption/.

Gonzalez, W. J. (2007a). Configuración de las Ciencias de Diseño como Ciencias de lo Artificial: Papel de la Inteligencia Artificial y de la racionalidad limitada,. In W. J. Gonzalez (Ed.), Las Ciencias de Diseño: Racionalidad limitada, predicción y la prescripción, 41-69. A Coruña: Netbiblo.

Gonzalez, W. J. (2007b). La contribución de la predicción al diseño en las Ciencias de lo Artificial. In W. J. Gonzalez (Ed.), Las Ciencias de Diseño: Racionalidad limitada, predicción y prescripción, 183-202. A Coruña: Netbiblo.

Gonzalez, Wenceslao J. (2008). La televisión interactiva y las Ciencias de lo Artificial. In M. J. Arrojo (Ed.), La configuración de la televisión interactiva: De las plataformas digitales a la TDT, xi-xvii. A Coruña: Netbiblo.

Ley, B., Ogonowski, C., Hess, J., Reichling, T., Wan, L. \& Wulf, V. (2014). Impacts of new technologies on media usage and social behaviour in domestic environments. Behaviour \& Information Technology - Thinking beyond the Box: Designing Interactive TV across Different Devices. 33(8), 815-828.

Mouseler, V. (2012). TV Social Fresh around the world. Conference presentes at Mipcom 2012, Cannes, France, October 11. Retrieved March 25, 2014, from http://blog.mipworld.com/2012/10/liveblog-fresh-social-tv/.

Networked Insights. (2012). Measuring Audience Engagement Through Social Data. Retrieved May 25, 2014 from http://www.networkedinsights.com/pdfs/Media_Case_Study-Audience_Sync.pdf.

Nielsen. (2011). The Relationship Between Social Media Buzz and TV Ratings. Retrieved June 6, 2014, from http://www.nielsen.com/us/en/newswire/2011/the-relationship-between-social-media-buzz-and-tv-ratings.html.

Nielsen (2012a). Study done by Cable \& Telecommunications Association for Marketing (CTAM). Retrieved May 4, 2014, from http://www.emarketer.com/Article/Facebook-Shows-Outsized-Influence-on-Social-TV/1009624.

Nielsen. (2012b). State of the Media. The Social Media Report 2012. Retrieved May 14, 2014, from http://www.nielsen.com/us/en/reports/2012/state-of-the-media-the-social-media-report-2012.html.

Nielsen. (2013). The future of TV is social. Retrieved May 23, 2014, http://www.nielsen.com/us/en/newswire/2013/the-future-of-tv-is-social.html .

Nielsen. (2014). The digital consumer. Retrieved May 17, 2014, from http://www.nielsen.com/content/dam/corporate/us/en/reports-downloads/2014\%20Reports/the-digital-consumer-re port-feb-2014.pdf.

Niiniluoto, I. (1993). The Aim and the Structure of Applied Research. Erkenntnis. Vol. 38, 1-21.

Servy, Caroline. (2012). The Wit: El auge de la \#SocialTV en Latinoamérica. In Informe Especial Social TV. Cannes: Mipcom.

Simon, H. (1996). The Sciences of the Artificial. Cambridge: The MIT Press, MA, $3^{\text {rd }}$ ed.

Tuomela, R. (1996). Intenciones conjuntas y acuerdo. In W. J. Gonzalez (Ed.), Acción e Historia. El objeto de la Historia y la Teoría de la Acción, 279-293. A Coruña: University of Coruña.

Twitter. (2012). Tune in with Twitter. Retrieved May 28, 2014, from https://tweet.twitter.com/tvbook .

The WitspottER. (2013). 10 Trends for Social TV in 2013. The new shows the world will be talking about. Conference presented at Mipcom 2013, Cannes, France, October 7-10. Retrieved April 28, 2014, from http://www.my-mip.com/RM/RM_MIPWORLD/2013/documents/pdf/resource-centre/whitepapers/miptv-mipcom- 
the-wit-ten-trends-social-tv-2013-whitepaper.pdf.

The WitspottER. (2014). Fresh Social TV around the world: 34 new TV shows from 22 countries generating the most social buzz. Conference presented at Miptv 2014, Cannes, France, April 7-10. Retrieved April 28, 2014, from http://www.my-mip.com/RM/RM_MIPWORLD/2014/documents/pdf/resource-center/whitepapers/miptv-mipcomwhite-paper-the-wit-fresh-social-tv-jan2014.pdf?v=635259754009452050.

Webdale, J. (2012). Sailing on the Social TV river. C21 Media. November 23. Retrieved April 23, 2014, from http://www.c21media.net/archives/94049 .

\section{Notes}

Note 1. These sciences of design have their roots in the sciences of the artificial studied by Herbert Simon in his very influential book: Simon, H. A., The Sciences of the Artificial, The MIT Press, Cambridge, MA, 3rd edition, 1996.

This paper offers an enlargement of his view, taking into account the contributions made in Gonzalez, W. J. (2012). Complejidad estructural en Ciencias de Diseño y su incidencia en la predicción científica: El papel de la sobriedad de factores (parsimonious factors). In W. J. Gonzalez (Ed.), Las Ciencias de la Complejidad: Vertiente dinámica de las Ciencias de Diseño y sobriedad de factores, 143-167. A Coruña: Netbiblo; and Gonzalez, W. J. The Sciences of Design as Sciences of Complexity: The Dynamic Trait. In H. Andersen, D. Dieks, W. J. Gonzalez, W. J., T. Uebel \& G. Wheeler (Eds.), New Challenges to Philosophy of Science, 299-311. Dordrecht: Springer.

Note 2. Shows covered in this special report include new shows launched in the above mentioned markets between January 1 and September 11, 2013, excluding off-schedule specials, one-offs linked to political, news and sports events, news, sports. Only new awards shows were included.

Note 3. Facebook likes and Twitter followers, as measured on the official account 1 day before the premiere of each new show launched over the period January - August 2013, as tracked in the Fresh TV database, i.e. 1270 titles measured.

\section{(c) $)$ EY}

This work is licensed under a Creative Commons Attribution 3.0 License 